\title{
REALIDADE E IMAGINÁRIO NAS IMAGENS DE CHERNOBYL ${ }^{1}$
}

REALITY AND IMAGINARY IN THE CHERNOBYL IMAGES

\author{
Dunya Azevedo * \\ dunya.azevedo@gmail.com
}

RESUMO: O presente artigo propõe uma reflexão sobre a fotografia contemporânea voltada para os vestígios do acontecimento histórico, e procura compreender como a memória do trauma se inscreve nas imagens. Para isso, tomei como corpus empírico algumas imagens do projeto La Zone, do fotógrafo francês Guillaume Herbaut. São imagens feitas na zona radioativa de Chernobyl, 24 anos após o acidente nuclear de 1986, na Ucrânia. A partir de um recorte seleciono algumas imagens do projeto, em que o fotógrafo joga com as ambiguidades e lacunas das imagens. Trata-se de imagens que apontam para a simultaneidade entre passado e presente e abrem espaço para o imaginário e a ficcionalização.

PALAVRAS-CHAVE: Fotografia documental, Memória, Chernobyl.

ABSTRACT: The present article proposes a reflection on contemporary photography focused on the traces of the historical event, and seeks to understand how the memory of trauma is inscribed in the images. For this, I take as an empirical corpus some images from the La Zone project, by the french photographer Guillaume Herbaut. They are images made in the radioactive zone of Chernobyl, 24 years after the nuclear accident of 1986, in Ukraine. From a clipping i select some images of the project in which the photographer plays with the ambiguities and gaps of the images. These are images that point to the simultaneity between past and present and open space for the imaginary and fictionalization.

KEYWORDS: Documentary photography, Memory, Chernobyl.

\section{Introdução}

No âmbito da fotografia contemporânea, um novo modo de testemunhar os acontecimentos históricos ganha espaço e importância. Buscando outra forma de abordar os fatos históricos, alguns fotógrafos se voltam para os vestígios do acontecimento e chegam ao local depois para recontar a história a partir do que restou. Frequentes em mostras de arte contemporânea, muitos desses trabalhos marcam uma relação próxima entre o fotógrafo e os fotografados e propõem um questionamento sobre as situações traumáticas vividas pelos

\footnotetext{
${ }^{1}$ Este artigo parte das reflexões desenvolvidas em minha tese de doutorado "As imagens do trauma após Chernobyl - entre restos e encenações", defendida em setembro de 2016 no Programa de Pós-Graduação em Comunicação Social da Faculdade de Filosofia e Ciências Humanas da Universidade Federal de Minas Gerais, Belo Horizonte, Minas Gerais, Brasil. Parte da pesquisa de doutorado foi realizada em estágio doutoral financiada pela Coordenação de Aperfeiçoamento de Pessoal de Nível Superior (CAPES) na Université Paris 1 - Panthéon Sorbonne de julho de 2014 a janeiro de 2015.

* Doutora em Comunicação Social pela Universidade Federal de Minas Gerais, com período sanduíche na Université Paris 1 Pantheon-Sorbonne (Paris/França);
} 
seres humanos. Ao atravessar o tempo, o fotógrafo aciona elementos da memória e da imaginação.

Pertencente a uma geração de artistas e fotógrafos atentos a essas inquietações contemporâneas e vindo de uma cultura essencialmente fotojornalística, Guillaume Herbaut, nascido na França em 1970, desloca-se do fotojornalismo para realizar alguns trabalhos pessoais que pudessem levá-lo a experimentar uma outra relação com a fotografia. A partir de sua experiência em lugares marcados por algum evento histórico como o bombardeamento de Hiroshima, a explosão da usina de Chernobyl ou a deportação dos judeus durante a II Guerra, o fotógrafo resgata histórias a partir do que ficou na esteira da catástrofe. Em seus trabalhos, Herbaut propõe um questionamento dos acontecimentos a partir da memória e uma reflexão a respeito da condição humana. Contra o esquecimento dos horrores da guerra e das grandes catástrofes, suas imagens são traços no presente de acontecimentos passados. O que o artista quer investigar, nesse caso, é como a catástrofe continua sua ação e como o passado se entrelaça ao presente de forma indissolúvel.

Os vestígios do trauma têm sido, muitas vezes, tema de trabalhos artísticos, em que a fotografia é importante ferramenta política e social. Entre outros artistas que adotaram a abordagem dos resíduos de catástrofes podemos citar a francesa Sophie Ristelhueber, que fotografou o que restou das guerras em Beirute, no início dos anos 1980, durante a Guerra civil no Líbano, e também produziu imagens nas fronteiras do Uzbequistão, Tadjiquistão e Azerbaijão. Em sua obra Fait (2009), a artista apresenta um trabalho fotográfico no Kuwait, revelando marcas da Guerra do Golfo Pérsico, que aconteceu em 1990. Alguns meses após o término do conflito, em 1992, Ristelhueber partiu para o deserto que foi palco da guerra e fotografou o terreno, explorando trincheiras, restos de tanques e de pertences pessoais, pilhas de cápsulas de explosivos detonados, minas terrestres e outros destroços deixados na areia. Fez também fotos aéreas das marcas de bombardeios e deslocamentos de tropas deixadas no solo. Outro artista que usa a fotografia para refletir sobre as consequências de catástrofes históricas, adotando também a abordagem dos vestígios, é o fotógrafo canadense Robert Polidori, nascido em 1951. A maior parte de suas imagens mostra ambientes vazios, revirados ou parcialmente destruídos, que foram abandonados depois de um choque violento. Entre seus trabalhos, destacam-se imagens feitas em Beirute, devastada pela guerra civil, e em Nova Orleans, destruída pelo furacão Katrina, em 2005. Assim como Guillaume Herbaut, 
Polidori fotografou, ainda, as cidades ucranianas de Chernobyl e Prypiat, quinze anos após o acidente nuclear de 1986.

Michel Poivert (2014) aponta para a tendência, no âmbito da arte, a partir dos anos 2000, à utilização de complexos de imagens: atlas, instalações, arquivos se tornaram uma forma de restaurar uma poética dos usos ${ }^{2}$. "O que vemos hoje no campo da arte, e aí a fotografia tem um papel decisivo, não é mais a imagem única enquadrada, mas sim em conjunto, em interação com o peso da história, com os jogos políticos da memória". (POIVERT, 2014, p. 25). Para ele, essa forma de testemunhar a história, que se distancia da abordagem fotojornalística é uma nova arte da memória (Poivert, 2010). E questiona: "o lugar da arte se tornou a nova mídia ou o testemunho reformulado teria encontrado um novo uso?"3 (2010, p. 108 , tradução minha).

Narrar, pela fotografia, os efeitos nefastos de uma catástrofe de grandes proporções que se deu há muitos anos e que causou profundos traumas em suas vítimas é um trabalho de resgate de algo que ficou no passado e que está em processo de apagamento. $O$ ensaio fotográfico produzido por Guillaume Herbaut na Zona interditada de Chernobyl e em seu entorno deu origem ao projeto La Zone, que se constitui de três objetos artísticos: um webdocumentário, o livro La Zone e a exposição de mesmo nome aberta ao público em abril de 2011 em Paris, por ocasião do aniversário de 25 anos do acidente na usina nuclear de Chernobyl $1^{4}$.

Nas imagens que compõem o projeto La Zone, percorremos com o fotógrafo locais abandonados, os escombros da usina, ruas vazias, e também entramos na intimidade de algumas pessoas das quais o fotógrafo se aproxima durante sua permanência na zona interditada. O que marca de forma mais evidente o trabalho fotográfico é o abandono, percebido na inscrição do tempo nos locais por onde o fotógrafo passa, na antiga usina, nos apartamentos evacuados, na paisagem em ruínas. Ao percorrer as imagens, percebemos os vestígios de uma catástrofe cujo perigo ainda existe e é invisível.

Sabemos que a edição e a escolha das imagens que formam as séries são importantes

\footnotetext{
${ }^{2}$ No original em francês: "poetique des usages".

${ }^{3}$ No original em francês: "Le lieu de l'art est-il devenu ce nouveau média où le témoignage réformé trouverait un nouvel usage?"

4 Os trabalhos de Guillaume Herbaut estão disponíveis no site do fotógrafo http://www.guillaumeherbaut.com/en/.
} 
para a apreensão da narrativa em um trabalho documental, e que cada uma das imagens adquire um valor específico de acordo com sua inserção junto às outras, já que elas partilham sentidos com as que estão próximas. No entanto, dentre as 75 fotografias que compõem o livro La Zone, selecionei apenas sete delas e reorganizei-as em grupos a partir de suas afinidades formais. Nas primeiras seis imagens, a presença de corpos em contato com o solo ou com superfícies contaminadas pela poeira radioativa apontam para uma certa ambiguidade da cena e abrem espaço para a ficcionalização como parte da obra documental. A figura 7, uma sequência de portas dos apartamentos abandonados na cidade de Prypiat aparece aqui como alegoria para as deformações dos corpos expostos ao alto nível de radioatividade. Testemunhos de vítimas da catástrofe de 1986, publicados no livro La Suplication, de Svetlana Alexievitch (1998) me forneceram importantes informações que me ajudaram na interpretação das imagens de Guillaume Herbaut aqui apresentadas.

Este recorte na narrativa da série tem o objetivo de compreender como a memória e o trauma decorrentes da catástrofe atravessam os corpos e os lugares, e criam novas teias de sentido, considerando o contexto específico em que estão inseridas. Ao trabalhar naquele lugar marcado pela história, Herbaut transforma o cenário em um jogo de temporalidades.

O projeto La Zone (2009-2011)

Em 2011, seria o aniversário de 25 anos do acidente de Chernobyl. Pensando em produzir um material que pudesse marcar essa data, Guillaume Herbaut, que já havia ido à Ucrânia para um projeto anterior, voltou àquele país algumas vezes entre 2009 e 2010 com o jornalista Bruno Masi, com o qual trabalhou para a publicação do livro La Zone e para o webdocumentário. A proposta era investigar sobre o que a vida havia se tornado em um lugar que ficou estigmatizado pelo acontecimento trágico e saber como viviam aquelas pessoas que insistiam em lá viver.

O método de trabalho de Guillaume Herbaut, à princípio, era livre. Antes de começar a fotografar, ele definia uma rota a partir do estudo do mapa do local, procurava os lugares, ia até lá, e as histórias apareciam. A geografia era seu guia, e, a partir dos encontros, a fotografia acontecia ou não. Com isso, o projeto podia ser repensado a cada dia, pois era a partir das trocas que ele estabelecia com as pessoas que o trabalho se desenvolvia. "Às vezes passo horas com as pessoas e não fotografo nada. Em outras situações, a fotografia acontece 
rapidamente", afirma Guillaume Herbaut. ${ }^{5}$

Nas imagens que compõem o projeto La Zone, Herbaut provoca encontros, constrói cenas e joga com as ambiguidades das imagens. O valor testemunhal dessas imagens não está limitado ao índice fotográfico, não se esgota no referente, mas incorpora algo que é da ordem da imaginação, dos afetos, da percepção e da memória. Guillaume Herbaut explica:

Esses lugares, esses fatos estão em mim desde minha adolescência. São acontecimentos que eu digeri como muitas pessoas, até integrá-los à minha cultura e à minha sensibilidade. São impressões de uma espécie de mistério que se faz presente em meu espírito. Sou consciente de dividir também a memória coletiva, e esse tema da memória foi e continua sendo importante para minha geração. [...] Mas o tratamento desta memória não é para mim uma abordagem de um historiador. Ao contrário, eu procuro os traços no presente dos acontecimentos passados, como por exemplo, as cicatrizes dos corpos, o mistério dos lugares. (HERBAUT, citado em POIVERT, 2010, p. 102, tradução minha)

Na madrugada de 26 de abril de 1986, uma série de explosões nos reatores da usina nuclear de Chernobyl, na Ucrânia, ocasionou o maior acidente nuclear do século XX. Muitas pessoas morreram nos primeiros dias após a explosão, outras milhares foram expostas a níveis de radiação capazes de provocar doenças como o câncer, e muitas crianças nasceram com anomalias. A radiação contaminou também lagos, rios, reservatórios e afetou a reprodução de animais.

Chernobyl é uma cidade localizada a $18 \mathrm{~km}$ da antiga usina nuclear e a $83 \mathrm{~km} \mathrm{da}$ capital Kiev. Devido ao nome da cidade, toda a área é chamada de Zona de Chernobyl. A apenas 3 quilômetros da usina, Prypiat era a cidade construída para alojar seus trabalhadores, onde moravam aproximadamente 30.000 pessoas. Um dia após o acidente, a cidade teve que ser evacuada, e os moradores foram aconselhados a levar com eles alguns poucos pertences, pois a informação oficial era de que a evacuação seria temporária. Com o tempo, Prypiat tornou-se uma cidade fantasma. Como, até nos dias atuais, a cidade tem um nível de radioatividade acima do normal, seus antigos habitantes nunca mais puderam voltar.

O ensaio fotográfico de Herbaut em Chernobyl é um trabalho relacionado à memória e à imaginação. A fotografia pode ser considerada uma ferramenta privilegiada para a reflexão

\footnotetext{
${ }^{5}$ Esta afirmação faz parte da entrevista "Guillaume Herbaut", concedida pessoalmente à autora deste artigo em novembro de 2014.
} 
sobre a experiência da memória, pois, ao mesmo tempo em que evoca o passado, ela pode servir como questionamento da realidade.

A rememoração, como ato de salvação de um passado e como forma de evitar que os fatos caiam no esquecimento, é, no pensamento grego, segundo aponta Gagnebin (2006), tarefa do poeta e posteriormente do historiador. Tanto a tarefa de um quanto a de outro não prescindem da imaginação. Imaginar é criar, projetar uma imagem a partir de restos, fragmentos do real que, compreendido na chave lacaniana, é o impossível, o inapreensível. Georgio Agamben (2012) lembra a teoria aristotélica da memória, que exerceu influência decisiva sobre a psicologia medieval e renascentista: "somente os seres que percebem o tempo relembram, e com a mesma faculdade com a qual percebem o tempo, isto é, com a imaginação" (Aristóteles citado em Agamben, 2012, p. 24). "A memória não é, de fato, possível sem uma imagem (phantasma), que é uma afecção, um páthos da sensação ou do pensamento" (AGAMBEN, 2012, p.24). Ao percorrer as imagens de Herbaut feitas a partir dos restos de Chernobyl, podemos perceber que o trabalho documental não prescinde da imaginação, que introduz o afeto no documental. Entre a fotografia e a coisa fotografada, opera-se um encontro.

Georges Didi-Huberman (2012) nos mostra, ainda, que a imaginação é política, e está relacionada à forma como o passado entrelaça-se de maneira indissolúvel com o presente. Sabemos que é também pelas imagens que (re)construímos a história. Sobre a importância da escritura da história e sua ligação com uma prática transformadora e redentora, devemos citar Walter Benjamin (1994), para quem a volta ao passado requer uma reparação, por meio da rememoração de um tempo esquecido, recalcado ou negado. A relação do passado com o presente não é de natureza temporal, mas imagética. Em Passagens, Benjamin afirma:

Não é que o passado lança sua luz sobre o presente ou que o presente lança sua luz sobre o passado; mas a imagem é aquilo em que o ocorrido encontra o agora num lampejo, formando uma constelação. Em outras palavras: a imagem é a dialética na imobilidade. Pois, enquanto a relação do presente com o passado é puramente temporal e contínua, a relação do ocorrido com o agora é dialética - não é uma progressão, e sim uma imagem, que salta. Somente as imagens dialéticas são imagens autênticas (isto é: não arcaicas), e o lugar onde a encontramos é a linguagem. (BENJAMIN, 2007, p. 504)

Ao organizar as imagens na série, Herbaut parece evidenciar, a partir da fotografia, pontos de convergência entre temporalidades distintas. Fotógrafo e fotografados estão juntos 
na complexidade de um tempo histórico composto pela mediação do evento traumático. $\mathrm{O}$ tempo histórico é o da dor e da memória de um passado que não passa.

Desconstruindo o topos cristão do anjo anunciador, Walter Benjamin em sua tese 9 do documento "Sobre o conceito de História" dá um novo sentido à mitologia cristã, ao observar a pintura de Paul Klee, Angelus Novus, sobre a qual o filósofo projeta seus próprios sentimentos. Ele diz que o "anjo novo" é levado pela tempestade, independentemente de sua vontade, em direção à repetição do passado: novas catástrofes, novas hecatombes, cada vez mais amplas e destruidoras. A tempestade, vista como metáfora para o progresso, impele o anjo ao futuro, e ele não consegue parar para recolher os fragmentos e os destroços das catástrofes. Com os olhos arregalados, ele se afasta de algo que vê e que o aterroriza.

Há um quadro de Klee que se chama Angelus Novus. Representa um anjo que parece querer afastar-se de algo que ele encara fixamente. Seus olhos estão escancarados, sua boca dilatada suas asas abertas. $\mathrm{O}$ anjo da história deve ter esse aspecto. Seu rosto está dirigido para o passado. Onde nós vemos uma cadeia de acontecimentos, ele vê uma catástrofe única, que acumula incansavelmente ruína sobre ruína e as dispersa a nossos pés. Ele gostaria de deter-se para acordar os mortos e juntar os fragmentos. Mas uma tempestade sopra do paraíso e prende-se em suas asas com tanta força que ele não pode mais fechá-las. Essa tempestade o impele irresistivelmente para o futuro, ao qual ele vira as costas, enquanto o amontoado de ruínas cresce até o céu. Essa tempestade é o que chamamos progresso. (BENJAMIN, 1994, p. 226).

Em direção contrária à filosofia hegeliana, que legitimava a ruína como etapa necessária da marcha da razão rumo ao progresso da humanidade, vários textos de Benjamin sugerem uma correspondência entre o progresso e a catástrofe que se repete infinitamente.

A fotografia de Guillaume Herbaut nos leva à rememoração do passado traumático que, em alguns momentos, parece se repetir na trama documental. Comparo o trabalho do fotógrafo ao do arqueólogo, que dá visibilidade às imagens escondidas, muitas vezes, recalcadas. O que vemos na fotografia é resultante da atitude do fotógrafo, que aborda o que está à sua frente com uma intenção. Mas, muitas vezes, a imagem tem uma autonomia e surge, diante de nós, como um fantasma, uma aparição. Refiro-me a algo de um inconsciente das imagens, para lembrar um termo utilizado por Maurício Lissovsky (2012), para quem a imagem é um sintoma. Lissovsky tem como base a teoria da sobrevivência das imagens, desenvolvida pelo historiador da arte Aby Warburg, a partir do que ele define como potências 
fantasmáticas das imagens.

Para Aby Warburg (apud DIDI-HUBERMAN, 2013) formas sobreviventes da cultura desaparecem e reaparecem ao longo da história e em momentos diferentes, constituindo afinidades entre si. O historiador refere-se a um "inconsciente das formas" e se aproxima das análises freudianas no campo das formações do inconsciente. Para Warburg (apud DIDIHUBERMAN, 2013, p. 272), as imagens são restos vitais da memória, "sedimentos mnêmicos, que se cristalizam , sobrevivem e ganham corpo".

A fim de compreender os modelos temporais, corporais e semióticos empregados por Warburg, Didi-Huberman parte do conceito freudiano de "formação do sintoma", pois tanto Warburg quanto Freud interrogam o mal-estar da cultura, seus recalcamentos. Assim como aquele clama por uma "psicologia da cultura", este também atribui importância à "história da cultura" como prolongamento da teoria psicopatológica. Assim como Freud descobre no sintoma um "regime descontínuo de temporalidade", Warburg identifica a mesma coisa na sobrevivência (DIDI-HUBERMAN, 2013, p. 273-274).

Warburg (apud DIDI-HUBERMAN, 2013, p. 278) se interessava pela "instauração do tempo na imagem". Para o historiador, os poderes da imagem estão relacionados com a memória inconsciente, que só se deixa apreender em momentos-sintoma e surge como um nó de anacronismos em que se entrelaçam várias temporalidades. Para Warburg, o tempo das imagens não é o tempo da história. O tempo das imagens é um tempo anacrônico.

Para Didi-Huberman (2015), a noção de anacronismo, de Aby Warburg, é como um método que permitiria compreender as relações entre imagem e história. Para ele, a história e a memória são narrativas construídas de fragmentos de elementos factuais e ficcionais recortados e remontados. Assim, a imagem seria entendida como uma operação de montagem, um lugar de possível contato com o real.

Em algumas imagens do projeto La Zone, o fotógrafo faz seu percurso e parece deixar que as imagens emerjam. Jogando com a realidade e a presença invisível do perigo, as imagens trazem a inscrição do trauma nos corpos, nas paisagens, nos lugares abandonados. $\mathrm{Na}$ narrativa da série fotográfica, o ritmo é ora acelerado, ora lento. Existem aí ambiguidades, conflitos e contradições que deixam frestas, aberturas para o imaginário. Em algumas das fotos, não sabemos se as pessoas fotografadas estão vivas ou mortas, não sabemos em que 
tempo estamos. Nesse percurso, passado e presente se sobrepõem, a morte se aproxima da vida.

A figura 1, uma das primeiras fotografias do livro La Zone, apresenta um homem caído no chão de asfalto - uma imagem forte, que evoca a violência sofrida pelo corpo abatido. 0 fotógrafo se aproxima, ilumina a cena, como quem investiga um crime. Uma luz dirigida clareia o chão, mostrando a aspereza do solo e parte do rosto do homem. Seus olhos estão fechados e, de sua face em perfil, sai uma substância vermelha como sangue, cuja artificialidade é facilmente percebida, devido à textura e à cor. Não podemos afirmar com certeza se se trata de um cadáver, de um homem bastante machucado ou se é apenas uma simulação. A aparente falsidade do sangue, somada ao impacto da cena que surge repentinamente, são elementos que levam a imagem à fronteira entre o real e o irreal.

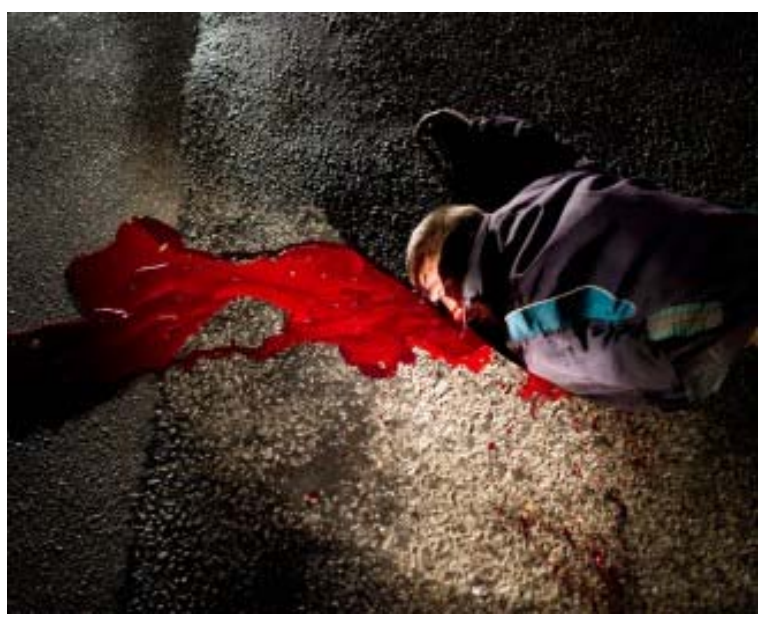

Figura 1- Fotografia do projeto La Zone de Guillaume Herbaut - Acervo pessoal

A imagem deste homem caído no asfalto não tem nenhuma relação direta com as vítimas do acidente nuclear. É uma imagem que poderia ser encontrada nos noticiários de criminalidade. Ela evoca a morte, o sofrimento, o horror. No momento da explosão, bombeiros foram chamados para, em vão, apagar o fogo que subia dos reatores da usina nuclear espalhando faíscas mortais por todo seu entorno. Esses bombeiros foram as primeiras vítimas fatais da catástrofe. Uma morte súbita no meio do caminho nos leva, de alguma forma, ao assombro provocado pela tragédia ocorrida no meio da noite, ao momento traumático de 1986.

Percorremos as páginas do livro La Zone com uma certa angústia e sofremos alguns sobressaltos no caminho. Temos a impressão de estar diante de um filme de suspense. $\mathrm{O}$ 
fotógrafo nos introduz a um mundo místico, onde a atmosfera é densa e ambivalente. Assim como o homem da imagem anterior, um gato, também supostamente morto, está caído no meio de uma estrada (figura 2). Nessa imagem, o sangue é mais real, mas o corpo machucado é pouco visível, pois ocupa um espaço mais restrito no quadro. Poderíamos pensar também que ele dorme, não fosse o índice de ferimento: a mancha de sangue ao lado do pequeno corpo. Ao olharmos com mais atenção para essa imagem, temos a impressão de que uma de suas patas está ferida, mas não sabemos o que teria provocado a morte ou o ferimento naquele animal. Podemos imaginar e conjecturar sobre as questões que essa foto nos traz.

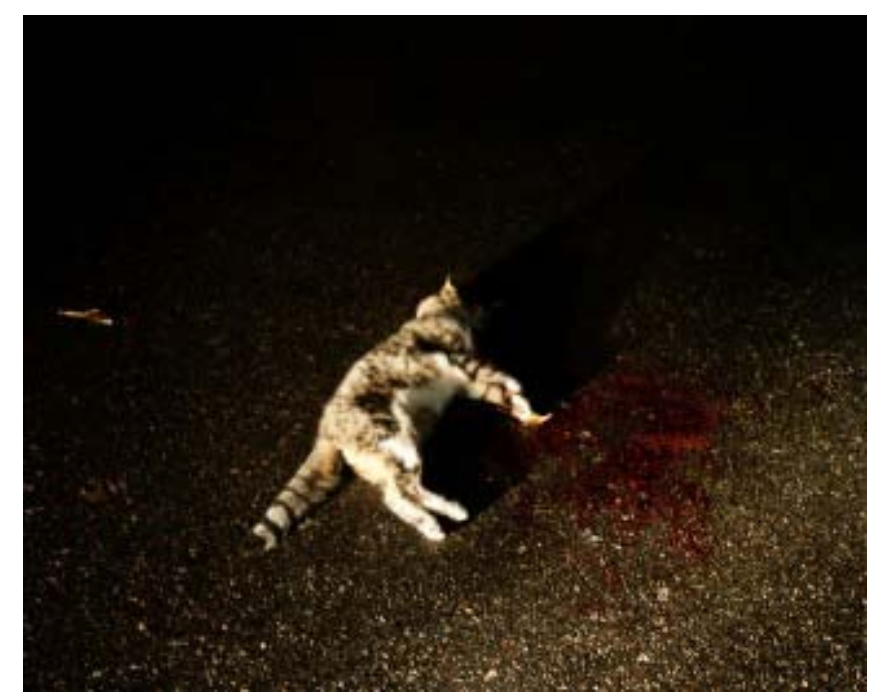

Figura 2 - Fotografia do projeto La Zone de Guillaume Herbaut - Acervo pessoal

A presença do felino nos faz lembrar de um depoimento de Nikolaï Fomitch Kalouguine, testemunha e vítima da catástrofe, publicado no livro La supplication, de Svetlana Alexievitch. No momento da evacuação do local, logo após a explosão da usina, em 1986, um anúncio no rádio alertava as pessoas sobre a proibição de levar com elas os gatos ou outros animais domésticos, que foram mortos ou ficaram entregues à própria sorte na zona de Chernobyl (ALEXIEVITCH, 1998, p. 45). Essa imagem poderia ser uma referência a tal passagem do livro ou, inconscientemente, o fotógrafo dá a ver essas imagens recalcadas do passado que povoam nosso imaginário. Devemos nos lembrar que essas fotografias foram feitas 24 anos após o acidente. No entanto, parece que a catástrofe ainda faz suas vítimas.

O fotógrafo continua sua incursão pela Zona de Exclusão de Chernobyl, onde irrompem cenas de morte. Não sabemos o que é um flagrante e o que é uma encenação. Em outro momento, nos deparamos com uma raposa de olhos entreabertos. Ela parece dar seu último suspiro sobre um banco de madeira carcomida pelo tempo (figura 3). Sabemos que os 
animais que ficaram no local do acidente àquela época sucumbiram à contaminação radioativa. Nessa foto a luz do sol ilumina o pêlo dourado do animal, que está sendo observado de perto. Seus olhos semiabertos e sua imobilidade denunciam a morte. Como se estivesse empalhada, sua carcaça resiste ao tempo. Mas por que ela está sobre um banco? Teria sido colocada ali para morrer? Essas imagens provocam dúvidas no espectador e o convocam a participar do jogo simbólico.

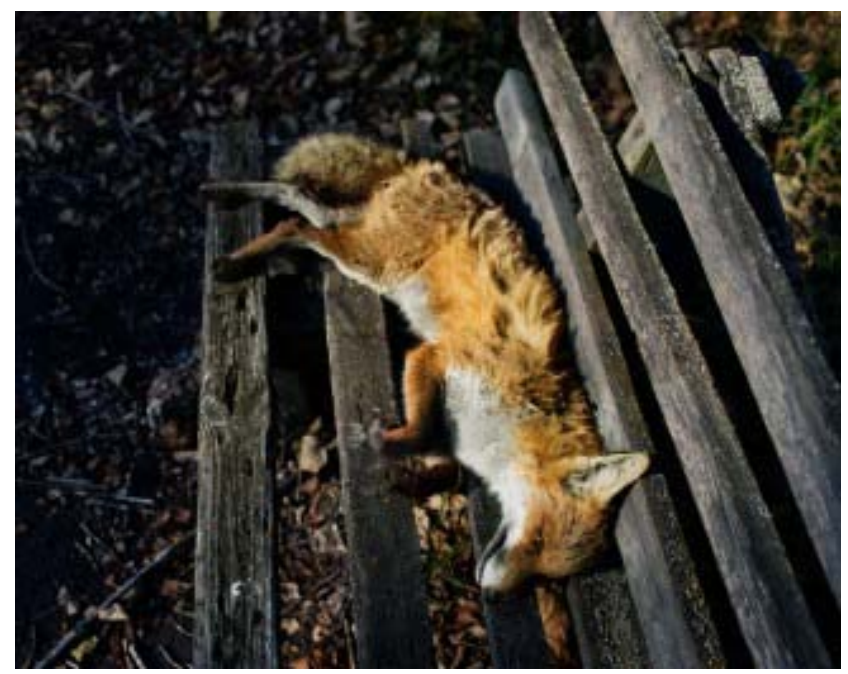

Figura 3 - Fotografia do projeto La Zone de Guillaume Herbaut - Acervo pessoal

Essas imagens nos remetem ao conceito de sobrevivência de Aby Warburg. A palavra Nachleben traduz bem o ponto central da obra warburguiana, esse "pós-viver": um ser do passado que insiste em sobreviver. As imagens, nesse retorno dos fantasmas, seriam consideradas como aquilo que sobrevive a uma dinâmica e uma sedimentação antropológicas tornadas parciais, virtuais, por terem sido, em larga medida, destruídas pelo tempo (DIDIHUBERMAN, 2013). O pensamento do historiador se constrói a partir das lacunas, das contramotivações, das aberrações, das impurezas das imagens e do tempo - base do seu conceito de sobrevivência. A ideia de sobrevivência ligada a fantasmas e sintomas tem, no campo das ciências antropológicas, uma ligação com o rastro.

A ambiguidade das imagens, dada pela posição e expressão dos corpos, não evidencia somente uma rede de indícios que formam a trama das aparências reais e ficcionais, mas reativa a memória da tragédia e dá forma a algo que ficou no passado. Através das frestas que as imagens oferecem à imaginação, o espectador é convidado a reviver os efeitos da tragédia. São restos de memórias que retornam nos gestos da morte, da violência, da dor, do trágico um homem caído no asfalto e mergulhado em uma suposta poça de sangue, animais mortos 
pelo caminho - O real aparece aqui como que "petrificado". São imagens anacrônicas, ligadas ao trauma, que voltam e nos remetem a outras imagens, outras tragédias, outras catástrofes, que se repetem infinitamente.

O trauma, segundo Sigmund Freud (1975, p. 93), resulta ou de "experiências sobre o próprio corpo do indivíduo ou de percepções sensórias, principalmente de algo vivido ou ouvido". Essas experiências ou impressões são marcantes e se tornam "esquecidas", latentes, resultando em perturbações posteriores, como a compulsão e a repetição da cena traumática. Como representações simbólicas da volta à situação traumática, essas imagens aparecem como as imagens oníricas, assim como acontece no sonho dos traumatizados, resultado da fixação no momento do trauma, (FREUD, 1976). Por um lado, o fotógrafo faz o papel do narrador desse sonho/pesadelo, que não é de um só traumatizado, mas é parte de um trauma coletivo.

O seguinte conjunto de imagens (figuras 4,5 e 6 ) é formado por fotos de pessoas estendidas no chão. Também essas imagens foram feitas na região de Chernobyl. Pelas informações do site do fotógrafo, o local onde essas pessoas foram fotografadas fica a 200 metros da zona proibida de Chernobyl. Se nas imagens anteriores os corpos do homem e dos animais parecem mortos, nessas, os fotografados parecem estar em estado de relaxamento.

O que nos chama a atenção é a posição dos corpos, cujos rostos só aparecem parcialmente. Essas pessoas parecem se divertir e relaxar no lugar que se tornou o novo paraíso para os ucranianos nouveaux riches ${ }^{6}$. Em todas as três fotografias deste grupo, os personagens encontram-se sozinhos. Aparentemente alheios ao que se passa ao redor, esses fotografados, assim como na primeira sequência de imagens, têm partes de seus corpos em contato direto com a materialidade dos elementos onde a radiação se depositou: água, areia, terra. O abandono dos corpos em contato com superfícies que um dia tiveram alto índice de radiação e que, em alguns lugares, ainda têm, sugere um esquecimento da tragédia e uma superação do trauma. Os personagens não se importam de se deixarem envolver pelos elementos da natureza que passaram a ser ameaças no trauma pós-catástrofe.

\footnotetext{
${ }^{6}$ Essa informação consta no site do fotógrafo http://www.guillaume-herbaut.com/en/chernobyl-riviera/
} 


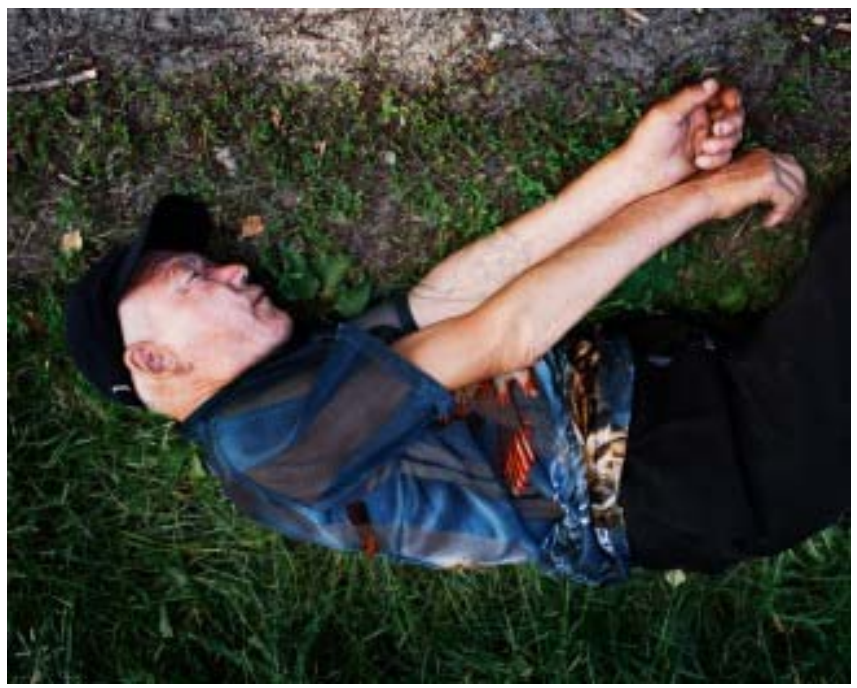

Figura 4- Fotografia do projeto La Zone de Guillaume Herbaut - Acervo pessoal

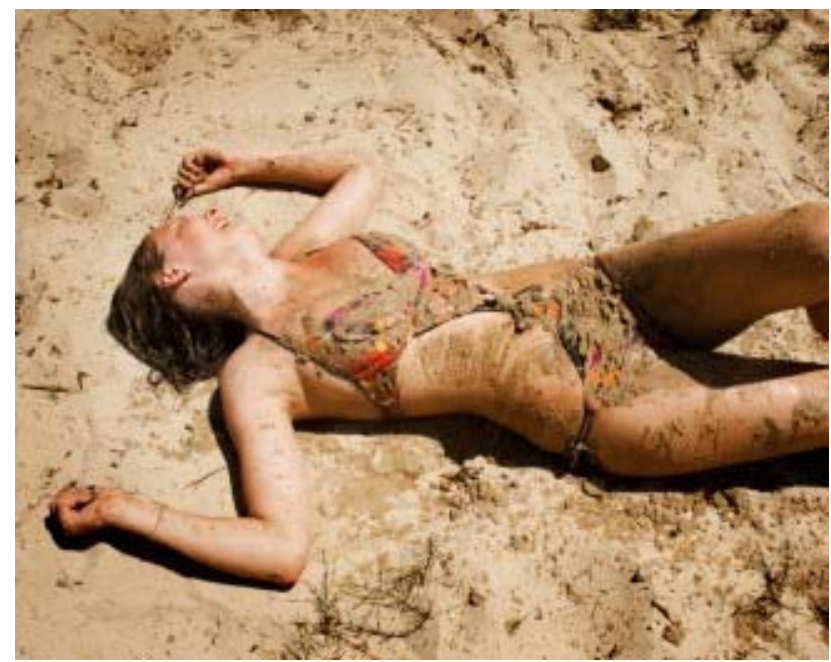

Figura 5 - Fotografia do projeto La Zone de Guillaume Herbaut - Acervo pessoal

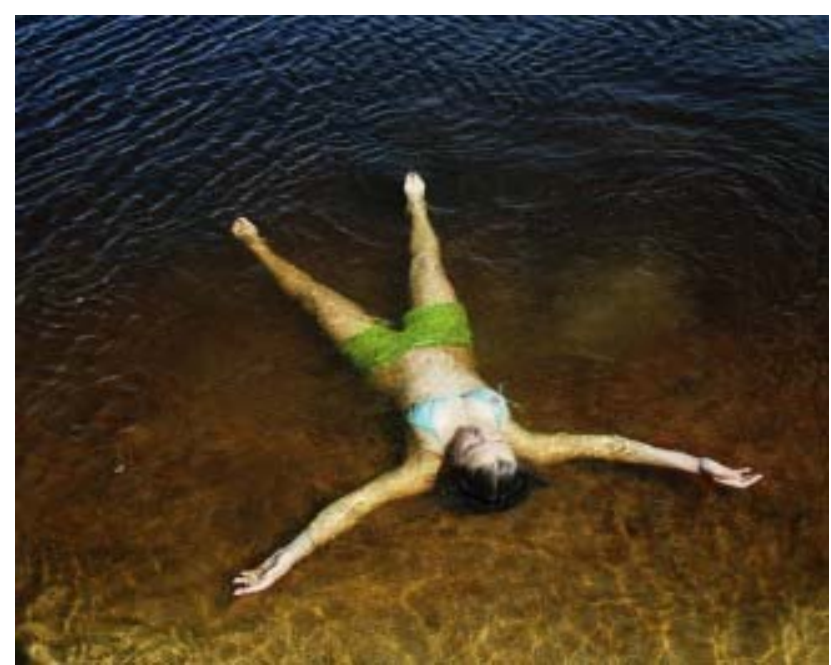

Figura 6 - Fotografia do projeto La Zone de Guillaume Herbaut - Acervo pessoal

Essas três fotografias nos levam para perto dos personagens em ângulo plongée. 0 
fotógrafo caminha, explora os lugares e, ao longo do caminho, encontra situações que vai registrando. Nessa sequência de imagens, assim como na anterior, o fotógrafo parece não interferir nas cenas, apenas as observa, se aproxima como um cão farejador, tentando descobrir algo que o leve para o tempo da catástrofe. Na figura 4, um homem parece dormir profundamente em contato com a grama, como se estivesse em seu próprio leito. Nas figuras 5 e 6, as pessoas parecem estar em estado de êxtase, de prazer, proporcionado pelo envolvimento dos corpos com a água e com a areia. Na figura 5, o gesto suspenso do corpo de uma mulher enlameado pela areia sugere uma entrega ao prazer. A areia envolve quase todo o corpo feminino iluminado pelo sol. Seu rosto é visto de lado, ela parece sorrir, mas pode também estar chorando. Essa imagem evoca a ambivalência da própria natureza daquele local, que pode ser tanto acolhedora quanto cruel. Na figura 6, a água está em degradé e passa de uma coloração ferrugem ao quase preto, que dramatiza a cena. O corpo semi-imerso está relaxado na água e tem a postura de um crucificado que flutua como se tivesse sido esquecido, abandonado, o que o aproxima, de certa forma, também da imagem da morte.

Nessas três últimas imagens (figuras 4, 5 e 6), as pessoas se deixam envolver pelos elementos da natureza que, aparentemente, não oferecem nenhum perigo, embora saibamos que a poeira radioativa ainda circula por aquele local. Na região, alguns locais se encontram totalmente abandonados e outros estão sendo redescobertos como lugares de diversão e tranquilidade. No entanto, o perigo ainda existe, e é invisível. Essas imagens de corpos que se entregam à natureza, aparecem aqui como dispositivo que permite um questionamento das atitudes de algumas pessoas que talvez tenham optado pela negação do perigo.

A figura 7 é uma sequência de portas envelhecidas dos apartamentos abandonados na cidade de Prypiat. Elas estão fechadas, quebradas, arranhadas e aparecem nas fotos emolduradas pelas paredes carcomidas. 


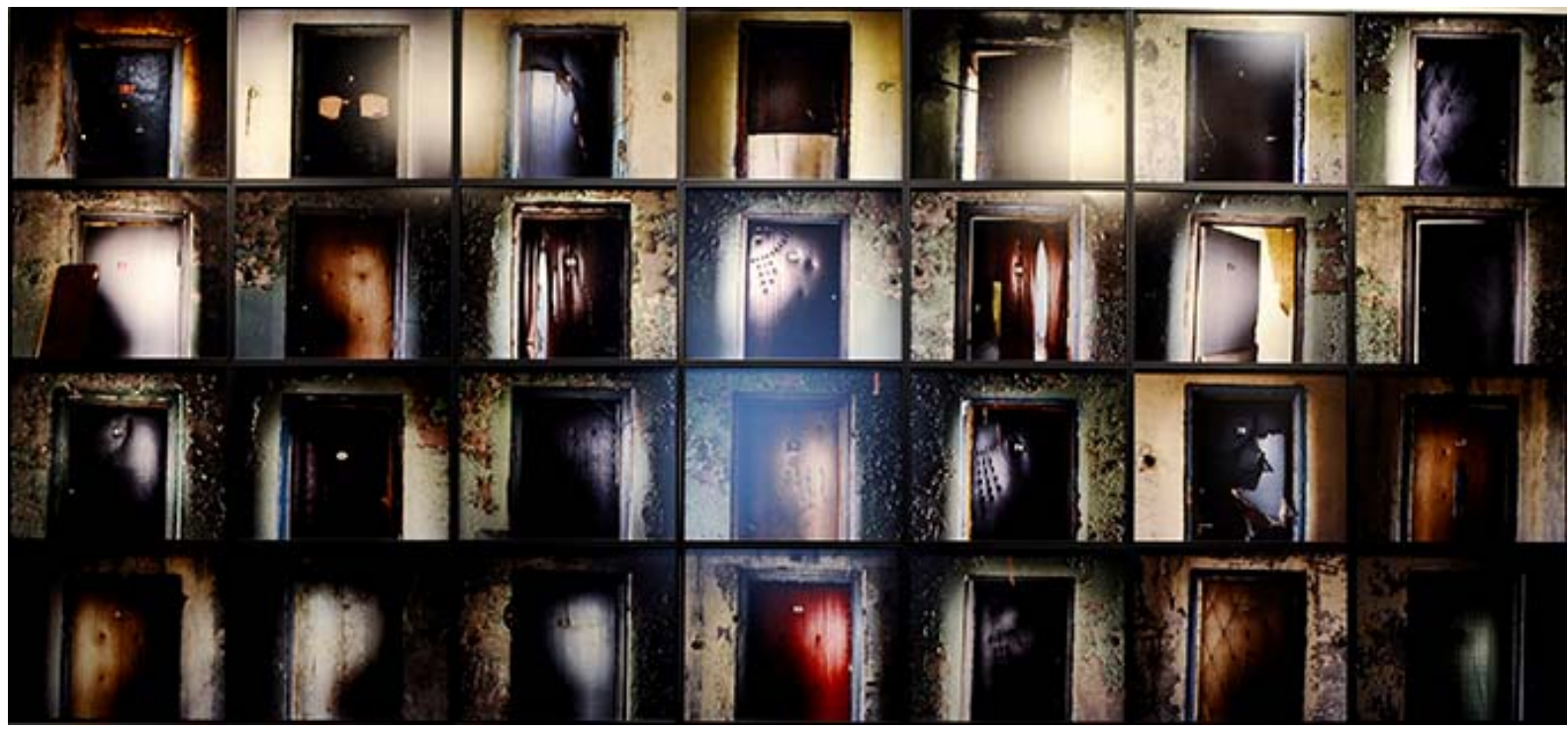

Figura 7 - Sequência de portas dos apartamentos abandonados em Prypiat (região de Chernobyl). Exposição "La Zone", de Guillaume Herbaut em Paris (2011). Fonte: http://www.guillaume-herbaut.com/en/doors-of-prypiat2/

Essas imagens de portas dos apartamentos evacuados em Prypiat estão sequenciadas como uma única imagem na exposição La Zone e intercaladas a outras imagens no livro La Zone. Elas voltam obsessivamente na sequência do livro e marcam, de forma simbólica, o esfacelamento das vidas que se foram. Não sabemos o que tem por trás dessas portas que se fecharam para sempre. Elas são como guardiãs de fragmentos de vidas, de restos de memórias daqueles que partiram às pressas. São, ainda, como as entradas dos túmulos, invioláveis e plenas de mistérios. Essas portas parecem ser de apartamentos de um mesmo imóvel abandonado, embora não tenham um padrão de cor nem de modelo. Algumas são ornadas com pinturas ou papéis decorativos coloridos, outras são pintadas ou mostram os desenhos da própria madeira crua. Nesses lugares de ruínas, não há vida, tudo é silêncio. A única ação é o trabalho do tempo, que, pouco a pouco, corrói e destrói tudo. Emolduradas pelas paredes, essas portas agonizam. As próprias paredes parecem condenadas a ferimentos eternos que não cicatrizam jamais. Como se tivessem suas peles descamadas, as paredes gritam e pedem socorro. As portas fazem eco a esse suplício, pois estão rachadas, quebradas, furadas, como feridas abertas pela ação do tempo. Algumas estão mesmo se descolando das paredes. Transfiguradas, elas mantêm um único sinal de identificação, que são os números dos apartamentos inscritos sobre algumas delas. Algumas têm um corte longitudinal e deixam entrever partes de seus miolos, como órgãos que saltam para fora do corpo. Outras têm furos e fissuras, a madeira se descola e deixa à mostra espumas e outras camadas de madeira. Suas 
espumas pulam para os lados, dependurando-se nas frestas, como um regurgitamento. A madeira já está, em uma delas, descolada da parede, a ponto de vermos, em volta da porta e em suas frestas, a luz que vem de dentro do imóvel. A morte aqui é lenta e agonizante.

Etienne Samain (2012) usa, como alegoria para pensar a imagem como fenômeno ligado à memória, o mistério e a complexidade das bonecas russas "que contém e escondem outras bonecas que se encaixam em um movimento materno e matricial expandido no tempo.

Numa passagem do livro La supplication, de Svetlana Alexievitch, uma sobrevivente da catástrofe faz um relato impressionante da morte de seu marido, bombeiro à época do acidente, que havia sido convocado para estancar o incêndio do reator, no dia da explosão da usina. Sem nenhuma proteção, ele e vários outros que trabalharam na contenção da radioatividade, foram encaminhados diretamente para o hospital, logo após terem cumprido sua missão. Nesse depoimento, a testemunha afirma que acompanhou o marido durante todo o tempo em que ele esteve hospitalizado até o momento de sua morte. Ela conta que nos momentos em que as enfermeiras tentavam levantá-lo, pedaços da pele do doente, que já estava em estágio avançado de deterioração, se descamavam e ficavam colados nas mãos dela, consequência do alto nível de radiação a que o corpo tinha sido exposto. Em outra passagem do livro, ela diz, ainda, que o corpo de seu marido se desfazia e partes dos órgãos saíam pela boca (ALEXIEVITCH, 1998).

Ao ler esse depoimento, somos levados a pensar, de forma alegórica, nas imagens da sequência de portas fotografadas - órgãos que saem pela boca. Indo um pouco além, podemos pensar também que, ao expelirem "entranhas", essas portas colocam para fora o que tentam esconder. Elas aparecem como instrumentos de obstrução. Alguma coisa nelas próprias e de lá de dentro dos apartamentos clama por atenção, algo que pulsa e pede para sair. O que está contido força sua saída e vai transfigurando o que está visível na imagem.

\section{Considerações finais}

A memória do trauma aparece nessas imagens da série de Guillaume Herbaut em La Zone de forma ambígua e lacunar. Nesse percurso, ele encontra corpos em contato com o chão e, em outros momentos de construção do projeto, o fotógrafo constrói cenas, dirige seus fotografados. As imagens das pessoas se intercalam às imagens dos locais em ruína. Ao acompanhá-lo pelas imagens, temos a impressão de estar em outro tempo, um tempo 
descontínuo, marcado pela "encenação" de imagens traumáticas. Ao que parece, a ambivalência das imagens permite ao fotógrafo criar constelações que apontam para distintas temporalidades em uma mesma fotografia, criando, assim, uma tensão entre real e imaginário. Mais do que registro do que vê, o que Guillaume Herbaut faz nessas fotografias é um ato de invenção.

Devemos lembrar que a vocação dessas imagens para a rememoração serve também a uma crítica do presente e abre uma possibilidade para o futuro, numa tentativa de reparação do sofrimento e da desolação das vítimas, como postulava Benjamin (1994). Com sua condição lacunar, elas têm a potência de resgatar o passado histórico, não para conhecê-lo tal como ele propriamente foi, mas para nos apoderarmos de uma lembrança. Pois, para Walter Benjamin (1994, p. 224), o resgate da história de um dado acontecimento dá-se a partir de "imagens que relampejam".

Como o retorno do recalcado, essas imagens voltam à superfície, reaparecem. A fotografia, nesse caso, talvez possa ser pensada como instrumento provocador desse retorno do recalcado, uma experiência para aquele que narra, assim como ocorre na psicanálise e no sonho, em que as imagens (autônomas) aparecem como lampejos.

\section{REFERÊNCIAS BIBLIOGRÁFICAS}

AGAMBEN, Giorgio. Ninfas. Trad. Renato Ambrosio. São Paulo: Hedra, 2012.

ALEXIEVITCH, Svetlana. La supplication. Tchernobyl, chronique du monde après l'apocalypse. Título original: Tchernobylsaïa Molitva. Moscou. Edição original: Ostojié, 1997. Trad. para o francês: Éditions Jean-Claude Lattès, 1998.

AZEVEDO, Dunya. As imagens do trauma após Chernobyl - entre restos e encenações. Tese de doutorado, Universidade Federal de Minas Gerais, Belo Horizonte, Minas Gerais. Disponível em: http://www.bibliotecadigital.ufmg.br/dspace/handle/1843/BUOS-AQVGDR, 2016.

BENJAMIN, Walter. Passagens. Belo Horizonte: São Paulo: Editora da UFMG, 2007.

BENJAMIN, Walter. Magia e Técnica, Arte e Política: ensaios sobre literatura e história da cultura. Obras Escolhidas; v. 1, 10. ed. São Paulo: Brasiliense, 1994, p. 36-39.

COTTON, Charlotte. A fotografia como arte contemporânea. São Paulo: Martins Fontes, 2010.

DIDI-HUBERMAN, Georges. Imagens apesar de tudo. Edição portuguesa, KKYM, Lisboa, 2012.

DIDI-HUBERMAN, Georges. A imagem sobrevivente. História da arte e tempo dos fantasmas Segundo Aby Warburg. Rio de Janeiro, Contraponto, 2013.

DIDI-HUBERMAN, Georges. Diante do tempo. Belo Horizonte, UFMG, 2015. 
FREUD, Sigmund. Fixação em traumas - o inconsciente. In: Conferências introdutórias sobre psicanálise (Parte III). v. XVI (1916-1917). Rio de Janeiro: Imago ed. Ltda, 1976, p. 323-336.

GAGNEBIN, Jeanne-Marie. Lembrar escrever esquecer. São Paulo: Ed. 34, 2006.

HERBAUT, Guillaume. Guillaume Herbaut Photography. Disponível em: http://www.guillaumeherbaut.com/en/.

HERBAUT, Guillaume; Masi, Bruno. La Zone, Paris: Naïve, 2011.

LISSOVSKY, Maurício. Para onde foi a senzala? Revista Zum 7, 11 de fevereiro de 2015. Disponível em https://revistazum.com.br/revista-zum-7/para-onde-foi-a-senzala/. Acesso em 20/01/2021.

POIVERT, Michel. La Photographie Contemporaine. Paris: Flammarion, 2010.

POIVERT, Michel. L'utopie Démocratique. In: La photographie un art en transition. n. 34, Août/Septembre/Octobre 2014b, p. 21-27. Revista ARTPRESS 2 - Paris, 2014.

SAMAIN, Etienne. As peles da fotografia: fenômeno, memória/arquivo, desejo. Visualidades, Goiânia, v. 10, n. 1, p. 155-164, jan-jul 2012. Disponível em: https://www.revistas.ufg.br/VISUAL/article/view/23089. Acesso em 20/11/2020. 